
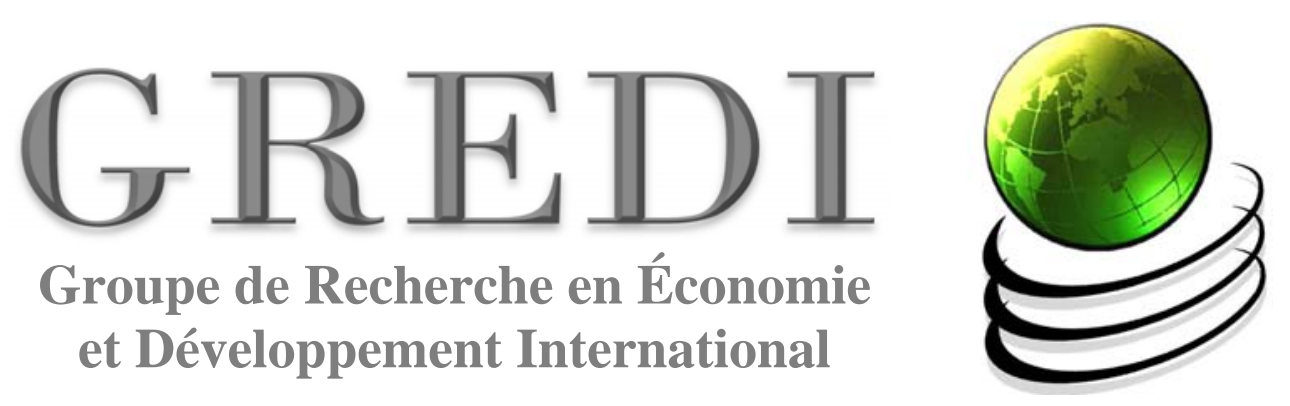

Cahier de Recherche / Working Paper
10-05

On the Links Between Unemployment Rate, Monetary Creation and the Value-added Sharing

Stéphane Mussard

Bernard Philippe 


\title{
On the Links Between Unemployment Rate, Monetary Creation and the Value-added Sharing
}

\author{
Stéphane Mussard* \\ LAMETA \\ Université Montpellier I
}

\author{
Bernard Philippe ${ }^{\dagger}$ \\ GEREM
}

Université de Perpignan

February, 2010

\begin{abstract}
In this paper, we investigate the analytical links between the rate of unemployment, monetary creation and how individuals share the value added in an economy with three types of agents : capital owners, managers and employees. This relationship relies on the fact that the rate of unemployment depends on many macroeconomic characteristics such as : creation of money, external balance of goods and services and mark-up pricing. The latter being decomposed into the expected margin rate and the growth rate of the unitary wage cost that characterize the primary value-added sharing.
\end{abstract}

Key-words and phrases : Mark-up pricing, Unemployment rate, Value added.

Classification JEL : E25, E24, C39.

${ }^{*}$ Lameta Université Montpellier I, Avenue de la Mer - Site de Richter - C.S. 79606, 34960 Montpellier Cedex 2 France. Tel : 33 (0)467158382 / Fax : 33 (0)4 67158467 - e-mail : smussard@adm.usherbrooke.ca, Associate researcher at GRÉDI, Université de Sherbrooke.

${ }^{\dagger}$ GEREM, Département des Sciences Economiques, Université de Perpignan, 52 Avenue Paul Alduy, 66860 Perpignan Cedex, France, E-mail : philippe@univ-perp.fr 


\section{Introduction}

At the beginning of his inauguration speech, Obama said "Our economy is badly weakened, a consequence of greed and irresponsibility on the part of some [...]" : In this paper, we propose an economic interpretation of what may be greed and irresponsibility in economies characterized by two things.

The first one is concerned with future. The second one is concerned with the roles that agents play in private.

(2) We impose, on the one hand, that agents make decisions under radical uncertainty, in the sense of Keynes (1936), that is, agents use subjective probabilities and do not know the true model of the economy.

(ı) We impose, on the other hand, that agents may play three different roles in the economy : capital owner, manager and employee. ${ }^{1}$ Those three roles are connected with into a particular hierarchy in order to deal with an endogenous repartition of the value added, which depends on conflicts between the three types of agents rather than on marginal productivity remunerations of each factor of production.

Following these two hypotheses, we focus on a modelling in which the unemployment rate variations constitute a variable depending on three factors : the ability of the banking sphere to create money, competitiveness of the economy, and the conflicts to share the value added. On this basis, it becomes clear that greed and irresponsibility of few agents may weakened the economy to such an extent that the rate of unemployment reaches a culminating point. This trend may appear when one is in search of more banking profitability, implying risky asset acquisitions, which imply in turn future losses on return equity, with a decreasing trust that reduce banks' ability to exert monetary creation, etc.

To discuss these stylized facts, we introduce in Section 2 the existence of radically uncertain future in order to formalize predictions that agents may make day to day. In Section 3, we expose the roles and the conflicts between agents for the sharing of the value added in a hierarchical economy. Section 4, is devoted to the relationship between unemployment and predictions. Introducing open economies in Section 5, we propose a formal link between unemployment rate variations and monetary creation. Going a step further, we present in Section 6 our economic interpretation of greed and irresponsibility, that is the link between monetary creation, the value-added sharing and the unemployment rate variations. Section 7 concludes.

\footnotetext{
${ }^{1}$ We suppose that those roles are not cumulative to avoid the characterization of non capitalist economies.
} 


\section{Radical uncertainty and predictions formalization}

\section{Notations.}

Let $\mathbb{N}$ be the set of integers and $\mathbb{N}^{*}$ its positive part. Let $t-1$ and $t$ the instants denoting the begin and the end of period $T$. Let $u_{t}$ be the unemployment rate at the instant $t, G D P_{t}$ the gross domestic product at the instant $t$. Let $\dot{X}_{t}$ be the growth rate of the variable $X$ between $t-1$ and $t$ and $X_{t}^{*}$ its expected value at the beginning of $T$.

We suppose that agents make decisions under radical uncertainty. Agents are not objectively aware of the type and of the widespread probability distribution functions of all random variables linked with their behavior. Consequently, we cannot represent the predictions elaboration by the way of the use of rational predictions in which the expected standard error is nil. For short, remember Keynes (1936, Chapter 12, Section 7, p. 162-163):

"[W]e are merely reminding ourselves that human decisions affecting the future, whether personal or political or economic, cannot depend on strict mathematical expectation, since the basis for making such calculations does not exist ; [...]".

On the other hand, we can no more represent the prediction elaborations by assuming that agents make use of subjective probability distribution functions. With this hypothesis, the determination of predictions would be represented by a calculus of conditional expectations in which the expected standard error is unknown. We reject this hypothesis too. Indeed, Hicks (1965) thought that the economists were unable to formalize "states of mind" which rule the determination of subjective distribution probabilities. He wrote :

"[T]he 'equilibrium' forces are (relatively) dependable; the 'disequilibrium' forces are much less dependable. We can invent rules for their working, and calculate the behavior of the resulting models; but such calculations are of illustrative value only. This is where 'states of mind' are of dominating importance; and states of mind cannot readily be reduced to rule [...]" (p. 83).

To represent the predictions elaboration in economies characterized by radical uncertainty of future we can only suppose two things. Firstly, that agents either know or can know the values of the variables of the previous period(s). Secondly, we assume that, bring together with their knowledge and their states of mind, information about the past allows them to make predictions about future values. This point of view is now adopted by authors such as Duménil and Levy (1996, p. 121-125) and Godley and Lavoie (2007, p. 16-18). In consequence, we take recourse to two main types of expectations :

Axiom 2.1 : Long Memory. At instant $t-1$ the elaboration of the predicted value of the variable $X$ for the end of period $T$ depends of all past values of $X$ :

$$
X_{t}^{*}=\prod_{\ell=1}^{n} \alpha_{\ell} X_{t-\ell}, \forall n \in \mathbb{N}^{*} \text { with } n \rightarrow \infty,
$$


where $\alpha_{\ell} \in[0,1](\ell \in\{1, \ldots, n\})$ are coefficients representing the influence of states of mind and knowledge during period $\ell$.

It is worth mentioning that in its current form Axiom (A1) is not quite different from adaptative expectations where past values enable one to elaborate mathematical expectations :

$$
X_{t}^{*}=\sum_{\ell=1}^{n} \alpha_{\ell} X_{t-\ell}, \alpha_{\ell} \in[0,1]
$$

which is the expected value over all past values. Axiom (A1) may also be viewed as a particular mean. Indeed, (A1) could have been written following the geometric mean :

$$
X_{t}^{*}=\left[\prod_{\ell=1}^{n} \alpha_{\ell} X_{t-\ell}\right]^{\frac{1}{n}}, \forall n \in \mathbb{N}^{*} \text { with } n \rightarrow \infty .
$$

The multiplicative expressions in (A1) and (A1') may be employed to characterize the link between unemployment rate variations and the sharing of the value added. Indeed, the multiplicative forms of the expectations enable us to further investigate growth rates of GDP and other variables. Accordingly, in the sequel we shall use (A1) only, although all results could have been derived under (A1') too. From a behavioral purpose, this means that agents keep in mind what happened in the past, for all periods, to elaborate expectations. On the contrary, they can analyze what happened in the two last periods only :

Axiom 2.2 : Short Memory. At instant $t-1$ the elaboration of the predicted value of the variable $X$ for the end of period $T$ is :

$$
X_{t}^{*}=\prod_{\ell=1}^{2} \alpha_{\ell} X_{t-\ell},
$$

where $\alpha_{1}, \alpha_{2} \in[0,1]$ are coefficients representing the influence of states of mind and knowledge during period 1 and $2 .^{2}$

\section{Hierarchy and the Sharing of the Value Added}

In order to further explore the characterization of the unemployment rate variations, let us admit that agents try to improve their own remuneration in the sense that they try to take benefit from the most important part of the value added.

For this purpose, let us imagine a very simple economy composed with three types of agents : capital owners, managers and employees. Managers organize the production and try to maximize the expected margin rate in order to defend the remuneration of the capital owners. Employees execute the strategies of production planned by the managers. An economy where the value added has to be shared is an economy where conflicts between agents may distort the traditional remuneration. Instead of looking at the traditional remuneration resulting from marginal productivity, we intend

\footnotetext{
${ }^{2}$ Obviously, the short memory concept is a particular case of the long memory one : (A1) $\subset($ A2). As indicated previously, the geometric mean may also be employed.
} 
to make a link between agent's expectations and conflicts between agents in order to show their implications on the value added and therefore on the unemployment rate variations. Conflicts may be viewed as lobbying resulting from the behavior of each type of agents : capital owners, managers and employees. Each agent tries to get the most important part of the cake, that is, the value added. Accordingly, behaviors have to be characterized by adjusted variables and in some cases predicted variables.

Claim 3.1 The measure of the expected margin rate $M R_{t}^{*}$ brings out the behaviors of capital owners, managers and employees with respect to the value added to be shared.

\section{Proof.}

Let $M R_{t}^{*}$ be the margin rate expected at the end of period $T$ and $W_{t}$ the sum of wages payed for employees and managers of the entire economy at the end of $T$. Let us also admit that the expected value added is sufficiently close to the $n G D P_{t}^{*}$. Following the conventions of national accountability, the expected margin rate is given by :

$$
M R_{t}^{*}=\frac{n G D P_{t}^{*}-W_{t}}{n G D P_{t}^{*}}
$$

Dividing numerator and denominator by the total number of employed individuals in the economy $N_{t}$ (employees and managers) yields :

$$
M R_{t}^{*}=1-\frac{w_{t}}{p_{t} \cdot G D P h_{t}^{*}},
$$

where $w_{t}$ is the nominal wage rate, $G D P h_{t}$ the real $G D P$ per head and $p_{t}$ is the deflator of $n G D P$ which is an increasing function of the components of the price vector at period $T$ (see Eq. 3). ${ }^{3}$

Let us now explain, why the measure of the expected margin rate is a relevant variable to conceive the conflicts for the sharing of the value added.

Agents.

( $)$ Capital owners may exert threats on managers in the sense that they may exert sanctions if the expected margin rate at the beginning of period $T$ is not totally reached at the end of period $T$. Let the cake be the value added, say $n G D P$ for ease of exposition, that agents have to share. Let $n G D P_{i}$ being the cake of firm $i$. Capital owners $i$ will receive the cake part they required at the end of period $T$, that is, the expected gross operating surplus ${ }^{4} G O P_{i t}^{*}:=n G D P_{i t}^{*}-W_{i t}$ if, at the end of period $T, G O P_{i t}=G O P_{i t}^{*}$. However, $n G D P_{i t}^{*}$ and $G O P_{i t}^{*}$ are neither necessary nor sufficient for capital owners to exert control over the sharing of the value added.

Capital owners (via the role of managers) have to control the remuneration and effort of employees, since the measure of the expected margin rate is a decreasing function of nominal wages

\footnotetext{
${ }^{3}$ It would be possible to insert $w_{t}^{*}$ instead of $w_{t}$ in order to capture the role of syndicates, that is, the possibility for $w_{t}$ to change within period $T$.

${ }^{4}$ Remember that the gross operating surplus $(G O P)$ used by national accounters is : $G O P_{t}=n G D P_{t}-W_{t}$.
} 
and an increasing function of real GDP per head. Then, capital owners have to be aware of the evolution of the margin rate. They make expectations to determine the amount of the margin rate of firm $i$ at the end of period $T$, that is, $M R_{i t}^{*}$. Note, that payments are function to expected returns of the firm's securities (for capital owners) and function of stock options (for managers). In this respect, if $M R_{i t}$ (at the end of period $T$ ) is significantly different to the expected margin rate at the beginning of period $T\left(M R_{i t}^{*}\right)$, then capital owners may threat managers. Managers may be directly licensed or indirectly, e.g., by the way of Wall Street Walk.

- Capital owners require a given profit rate for the end of period $T$. The profit rate being not easily computable, we then restrict our attention to key variables that represent capital owners intermediate objectives only : $M R_{i}^{*}$ (resulting from $n G D P_{i}^{*}$ and $G O P_{i}^{*}$ ).

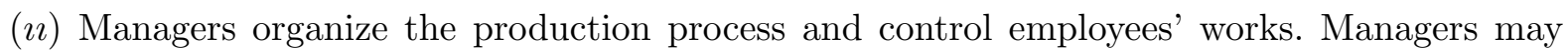
constrain employees (carrot or threats policies) exactly in the same way than capital owners threat managers : if the results at the end of $T$ are not reached, then the sanction may be the lay-off, so that managers exert control over the amount of employed persons in firm $i\left(N_{i t}\right)$. Alternatively, the sanction may be the absence of bonus at the end of period $T$ for employees or a cut-off of nominal wages $\left(w_{i t}\right)$. On the contrary, in order to reach his objectives, managers may improve the nominal wage in order to increase the labor productivity of the firm $G D P h_{i t}=\frac{n G D P_{i t}}{N_{i t}}$ and so $n G D P_{i t}$ (which is capital owners' intermediate objective). Managers have also the possibility to exert no threats on employees in order to maintain the relationship and the trust between them (this can be important for manager's credibility and for their future collaborations). In this respect, mark-up pricing enables managers to obey capital owners preferences, that is, to enhance prices $p_{i t}$ at the beginning of period $T$ in order to increase $n G D P_{i t}$ and to preserve their relationship with employees. For this reason, managers have to make expectations on labor productivity $G D P h_{i t}^{*}$ since the level of sells is not known at the beginning of $T$.

- The key variables that managers may adjust are $: N_{i t}, w_{i t}$ and $p_{i t}$ (in function of $G D P h_{i t}^{*}$ and $\left.n G D P_{i t}^{*}\right)$.

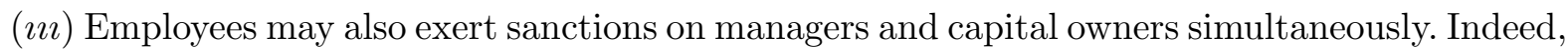
the well-known employee's lobbying is the syndicate, which exert pressures on wages and efforts.

- The adjusting variables are in this case : $w_{i t}$ and $G D P h_{i t}$. Note that $G D P h_{i t}=\delta \eta G D P h_{i t}^{*}$ with $\eta \leq 1$ representing the acceptation degree of working conditions and $\delta \leq 1$ representing the validation degree of the offered production.

\section{Aggregation.}

In order to deal with the entire economy we make the aggregation over the $n$ firms of the economy (the aggregation being either sums or weighted means) :

$$
w_{t}=\frac{1}{n} \sum_{i=1}^{n} w_{i t}, p_{t}=\frac{\sum_{i=1}^{n} p_{i t} G D P_{i t}}{G D P_{t}}, G D P_{t}=\sum_{i=1}^{n} G D P_{i t}, N_{t}=\sum_{i=1}^{n} N_{i t}, G D P h_{t}=\frac{G D P_{t}}{N_{t}}
$$


To recap, we get :

Figure 1. Hierarchy and Role of the Agents at Period $T$

Beginning of Period $T: \quad$ Capital Owners require $M R_{t}^{*}$

$\Downarrow$

Beginning of Period $T$ : Managers fix $N_{t}, p_{t}$

$\Downarrow$

Beginning of Period $T: \quad$ Employees contribute to fix $w_{t}$

During Period T: Employees take or modify $\eta$

Note that the expected margin rate represent the "remuneration" of capital owners (in percentage) when wages has been payed. It is easy to see that our measure of expected margin rate characterizes the process of the value-added sharing.

( $)$ The expected margin rate is an increasing function of the gap between the expected value added and the remuneration of the employees (see equation 1). Accordingly, the sharing of the value added is relevant with an analysis in terms of conflicts and contracts between capital owners and wage owners by the way of managers' role.

(ı) The expected margin rate is an increasing function of mark-up pricing and of the expected real GDP per head. It is a deceasing function of nominal wages (equation 2). Therefore, our measure of the expected margin rate enables us to introduce the behavior of the managers.

( $2 \imath$ ) The expected margin rate is a decreasing function of the nominal wage rate (equation 2). Again, our measure of the expected margin rate enables us to introduce the behavior of the employees.

\section{Characterizing the rate of unemployment with basic expectations}

In the previous Section, we have characterized the variations of the unemployment rate between periods $T-1$ and $T$ from two types of managers' elaboration of expectations : based on many past periods (long memory) or based on few past periods only (short memory). ${ }^{5}$

We propose many ways to characterize the variation of the rate of unemployment before carrying out (in Section 5) a link between this variation, monetary creation and the modalities of how the value added is shared. We derive this variation with respect to the use of the traditional definition of the rate of unemployment itself issued from the active population definition.

\footnotetext{
${ }^{5}$ This is not the aim of the paper to introduce risk aversion in the model, but long and short memory may be connected with a risk averse manager or a risk lover, respectively.
} 
Definition 4.1 The rate of unemployment at period $T$ is a decreasing function of the total number of persons employed in the economy at period $T\left(N_{t}\right)$ and an increasing function of the active population at period $T A P O P_{t}$ :

$$
u_{t}=1-\frac{N_{t}}{A P O P_{t}}
$$

Theorem 4.1 From definition (A3), if managers behave according to (H2) and (A1), then:

$$
u_{t}-u_{t-1} \approx \sum_{\ell=1}^{n}\left(\dot{\beta}_{\ell}-\dot{\alpha}_{\ell}\right)+\sum_{\ell=1}^{n}\left(G \dot{D P} h_{t-\ell}-G \dot{D} P_{t-\ell}\right)+\dot{R} A_{t}+W \dot{P} O P_{t} .
$$

\section{Proof.}

We know from (A3) that :

$$
u_{t}=1-\frac{N_{t}}{A P O P_{t}}
$$

We know that :

$$
N_{t}=\frac{G D P_{t}^{*}}{G D P h_{t}^{*}}
$$

then

$$
u_{t}=1-\frac{\frac{G D P_{t}^{*}}{G D P h_{t}^{*}}}{A P O P_{t}}
$$

If managers behave according to (H2), that is, they fix the level of employment and they defend the interests of capital owners, then :

$$
u_{t}=1-\frac{G D P_{t}^{*}}{G D P h_{t}^{*} \cdot A P O P_{t}} .
$$

This means that managers make expectations to choose their 'optimal' level of employment. Now, suppose that managers' expectations are (A1), thus :

$$
u_{t}=1-\frac{\Pi_{\ell=1}^{n} \alpha_{\ell} G D P_{t-\ell}}{\Pi_{\ell=1}^{n} \beta_{\ell} G D P h_{t-\ell} \cdot A P O P_{t}},
$$

where $\alpha_{\ell}$ and $\beta_{\ell}$ are weights associated with the expectations of $G D P_{t}^{*}$ and $G D P h_{t}^{*}$, respectively. Subsequently, as for all $\ell \in\{1,2, \ldots, n\} A P O P_{t}=R A_{t} . W P O P_{t}$, where $R A_{t}$ is the rate of activity and where $W P O P_{t}$ is the working-age population, it then follows that:

$$
1-u_{t}=\frac{\Pi_{\ell=1}^{n} \alpha_{\ell} G D P_{t-\ell}}{\Pi_{\ell=1}^{n} \beta_{\ell} G D P h_{t-\ell} \cdot R A_{t} \cdot W P O P_{t}} .
$$

The same reasoning applies for the period $T-1$ :

$$
1-u_{t-1}=\frac{\Pi_{\ell=2}^{n} \alpha_{\ell} G D P_{t-\ell}}{\Pi_{\ell=2}^{n} \beta_{\ell} G D P h_{t-\ell} \cdot R A_{t-1} \cdot W P O P_{t-1}} .
$$

Remark that $\log (5)$ minus $\log (6)$ yields (growth rates) :

$$
u_{t}-u_{t-1} \approx \sum_{\ell=1}^{n}\left(\dot{\beta}_{\ell}-\dot{\alpha}_{\ell}\right)+\sum_{\ell=1}^{n}\left(G \dot{D} P h_{t-\ell}-G \dot{D} P_{t-\ell}\right)+\dot{R} A_{t}+W \dot{P} O P_{t} .
$$


This result shows that GDP and GDPh exert an important inertia on the rate of unemployment variations as well as the way that managers predict the values of GDP and GDPh (via $\alpha$ and $\beta)$. Consequently, within an environment in which the value added has to be shared, managers' expectations made about the intensity of futures activities is crucial. ${ }^{6}$

Theorem 4.2 From definition (A3), if managers behave according to (H2) and (A2), then :

$$
u_{t}-u_{t-1} \approx \dot{\beta}_{1}-\dot{\alpha}_{1}+G \dot{D} P h_{t-1}-G \dot{D} P_{t-1}+\dot{R} A_{t}+W \dot{P} O P_{t} .
$$

\section{Proof.}

Analogous to Theorem 4.1.

Expressions (7) or (8) enable time lags in $G D P$ and $G D P h$ to be introduced. From a behavioral purpose, this means that managers analyze the results of their activity at the end of period $T-1$ (throughout $G \dot{D} P h_{t-1}$ and $G \dot{D} P_{t-1}$ ) and therefore adjust the level of employment at the beginning of period $T$ by making expectations on theses variables for the end of period $T$.

Let us now analyze what happens when the monetary creation and the opening of economies are formalized in our model.

\section{Monetary Creation, value-added Sharing and Unemployment}

In this section, we shall demonstrate the relevance of our two previous Theorems in open economies in order to introduce the ability of each economy to defend its competitiveness in a globalized world. It is worth mentioning that our goal is to connect unemployment rate variations with the modalities of the value-added sharing. This was partly achieved in the previous Section in which mangers' elaboration of expectations play a considerable role in the composition of unemployment rate variations. For our purpose, we introduce two definitions, which are identities relying on national accountability concepts.

Definition 5.1 : Demand side of GDP. The nominal GDP at period $T$ ( $\left.n G D P_{t}\right)$ is defined to be :

$$
n G D P_{t}=C_{t}^{H}+I_{t}+E X P_{t}-I M P_{t},
$$

where $C_{t}^{H}$ is the overall household consumption spending at the end of period $T$, and where $I_{t}$, $E X P_{t}$ and $I M P_{t}$ are respectively : investments, exportations and importations computed at the end of period $T$.

Definition 5.2 : Income side of GDP. The nominal GDP at period $T\left(n G D P_{t}\right)$ is defined to be :

$$
n G D P_{t}=R_{t}-R R_{t}+R V_{t}
$$

\footnotetext{
${ }^{6}$ It is worth mentioning that Mussard and Philippe (2009) obtained unemployment variations with Okun's law. This research is relatively different in the sense that the elaborations of expectations and the modalities of how the value added has to be shared are introduced in the model.
} 
where $R_{t}$ stands for the agents' disposal income at the end of period $T, R R_{t}$ the sum of all income flows that residents receive from the rest of the world at the end of $T$, and $R V_{t}$ the sum of all income flows that residents pay for the rest of the world at the end of period $T$.

Let us now introduce a time-lag dependency :

Definition 5.3 : Robertson's time lag. The disposal income at the end of period $T-1$ enables consumption to be financed during period $T$ and savings $\left(S_{t}\right)$ to be accumulated during $T$ :

$$
R_{t-1}=C_{t}^{H}+S_{t}
$$

From the debate between Keynes and Robertson about how the consumption has to be financed (with $R_{t}$ or $R_{t-1}$ ), we opt for Robertson's hypothesis. Indeed, it can be easily proved that Keynes' hypothesis $R_{t}=C_{t}^{H}+S_{t}$ leads to the identity between investment $(I)$ and savings $(S) .{ }^{7}$ However, as explained in our next results the disequilibrium between $I$ and $S$ is one of the corner stone of our model. According to (B0)-(B2) it is possible to compute the growth rate of real GDP, and consequently to characterize the variations of the unemployment rate according to : the managers' expectations, the competitiveness of the economy and the gap between $I$ and $S$. The first case is related to long memory :

Theorem 5.1 From definitions (A3) and (B0)-(B2), if managers behave according to (H2) and (A1), then :

$$
\begin{aligned}
u_{t}-u_{t-1} \approx & \sum_{\ell=1}^{n}\left(\dot{\beta}_{\ell}-\dot{\alpha}_{\ell}+G D \dot{P} h_{t-\ell}\right)+R A_{t}+W \dot{P} O P_{t} \\
& +\sum_{\ell=1}^{n}\left(-\frac{I_{t-\ell}-S_{t-\ell}}{G D P_{t-\ell-1}}-\frac{E X P_{t-\ell}-I M P_{t-\ell}}{G D P_{t-\ell-1}}-\frac{R R_{t-\ell-1}-R V_{t-\ell-1}}{G D P_{t-\ell-1}}+\dot{p}_{t-\ell}\right)
\end{aligned}
$$

Proof.

From (B2) : $S_{t}=R_{t-1}-C_{t}^{H}$. As (B1) yields : $R_{t-1}=n G D P_{t-1}+R R_{t-1}-R V_{t-1}$, then $C_{t}^{H}=$ $n G D P_{t-1}+R R_{t-1}-R V_{t-1}-S_{t}$. We know from (B0) that : $n G D P_{t}=C_{t}^{H}+I_{t}+E X P_{t}-I M P_{t}$. Therefore, $n G D P_{t}-n G D P_{t-1}=I_{t}-S_{t}+E X P_{t}-I M P_{t}+R R_{t-1}-R V_{t-1}$. Dividing both sides by $n G D P_{t-1}$ and using the inflation rate $\dot{p}_{t}$ as the deflator of $n G \dot{D} P$ gives the growth rate of real $G D P$ :

$$
G \dot{D} P_{t}=\frac{I_{t}-S_{t}+E X P_{t}-I M P_{t}+R R_{t-1}-R V_{t-1}}{G D P_{t-1}}-\dot{p}_{t}
$$

We know that :

$$
1-u_{t}=\frac{\Pi_{\ell=1}^{n} \alpha_{\ell} G D P_{t-\ell}}{\Pi_{\ell=1}^{n} \beta_{\ell} G D P h_{t-\ell} \cdot R A_{t} \cdot W P O P_{t}} .
$$

Hence, we deduce from Theorem 4.1 that :

$$
u_{t}-u_{t-1} \approx \sum_{\ell=1}^{n}\left(\dot{\beta}_{\ell}-\dot{\alpha}_{\ell}+G \dot{D P} h_{t-\ell}-G \dot{D P} \dot{P}_{t-\ell}\right)+R \dot{A} A_{t}+W \dot{P} O P_{t} .
$$

\footnotetext{
${ }^{7}$ The proof can be sent upon the request of the author.
} 
From Eq. (10), we get :

$$
\begin{aligned}
u_{t}-u_{t-1} \approx & \sum_{\ell=1}^{n}\left(\dot{\beta}_{\ell}-\dot{\alpha}_{\ell}+G D \dot{P} h_{t-\ell}\right)+R \dot{A} A_{t}+W \dot{P} O P_{t} \\
& +\sum_{\ell=1}^{n}\left(-\frac{I_{t-\ell}-S_{t-\ell}}{G D P_{t-\ell-1}}-\frac{E X P_{t-\ell}-I M P_{t-\ell}}{G D P_{t-\ell-1}}-\frac{R R_{t-\ell-1}-R V_{t-\ell-1}}{G D P_{t-\ell-1}}+\dot{p}_{t-\ell}\right) .
\end{aligned}
$$

If however agents adjust their behaviors according to few past periods, then we get the short memory case :

Theorem 5.2 From definitions (A3) and (B0)-(B2), if managers behave according to (H2) and (A2), then :

$$
\begin{aligned}
u_{t}-u_{t-1} \approx & -\sum_{\ell=1}^{n}\left(\dot{\alpha}_{\ell}-\dot{\beta}_{\ell}\right)+R A_{t}+W \dot{P} O P_{t} \\
& -\frac{I_{t-1}-S_{t-1}}{G D P_{t-2}}-\frac{E X P_{t-1}-I M P_{t-1}}{G D P_{t-2}}-\frac{R R_{t-2}-R V_{t-2}}{G D P_{t-2}}+\dot{p}_{t-1} .
\end{aligned}
$$

Proof.

Use Theorem 5.1.

Discussion.

These previous results indicate that the unemployment rate variations are unambiguously dependent to two types of monetary creation.

( $) \mathbf{I}-\boldsymbol{S}:$

Note that :

$$
I_{t-\ell}-S_{t-\ell}>0 \Longleftrightarrow I_{t-\ell}+C_{t-\ell}^{H}>S_{t-\ell}+C_{t-\ell}^{H}, \forall \ell \in\{1, \ldots, n\} .
$$

Using (B2) yields :

$$
I_{t-\ell}+C_{t-\ell}^{H}>R_{t-\ell-1}
$$

In this case, the disposal cannot compensate for the spending flows of consumption and investment. This means that whenever $I-S>0$ agents have the possibility to consume and to invest more than the amount of their disposal incomes. Indeed, $I_{t-\ell}+C_{t-\ell}^{H}$ represents the spending flow of agents during $t-\ell$ whereas $S_{t-\ell}+C_{t-\ell}^{H}$ represents their disposal incomes at the end of period $t-\ell-1$. Consequently, agents have the possibility to consume and to invest more than their disposal incomes, that is, $I_{t-\ell}-S_{t-\ell}>0$ if, and only if, there is creation of money. Consequently, the equation (9) is consistent with the role of the banking system and the credits that the commercial banks are able to grant. 


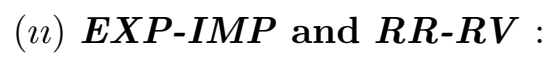

Let us now turn to the other differences : $E X P_{t-1}-I M P_{t-1}>0$ and $R R_{t-2}-R V_{t-2}>0$. These two expressions imply monetary creation too. For instance, let us take the case of Germany and China, for which the amount of exportations is significant. They receive from other countries many devises the central banks have to convert into domestic money, so that the creation of money is the consequence of the competitiveness of the economy. The competitiveness is twofold : either ascribable to attractive manufacturing products $\left(E X P_{t-1}-I M P_{t-1}>0\right)$ or to financial products in the case where $R R_{t-2}-R V_{t-2}>0$.

Finally, we get two types of monetary creation being oppositely connected with the unemployment rate variations :

( $)$ the former is associated with the agents' behavior in each economy : the ability of agents to demand credits and the ability of the bank system to deliver credits (this being particularly difficult during the crisis);

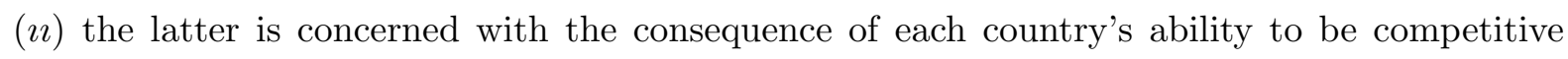
compared with others.

\section{Unemployment and manager's mark-up pricing}

In the last two Sections, we have demonstrated that the unemployment rate variations are a function of agents' expectations and monetary creation. Furthermore, as shown in Figure 1, the elaboration of expectations is strongly dependent to the modifications of the value added shares between periods $T-1$ and $T$. Accordingly, the key variables (see Figure 1 supra) that characterized the behavior of the agents may be replaced by their growth rates if we suppose that the sharing of the value added is a dynamic problem :

Proposition 6.1 The growth rate of the margin rate between $T-1$ and $T \dot{M} R_{t}$ is :

$$
\begin{gathered}
\dot{M R_{t}^{*}}=f\left(\dot{p}_{t}, \dot{w}_{t}, G \dot{D P P} h_{t}^{*}\right), \text { such as } \\
f^{\prime}\left(\dot{p}_{t}\right)>0, f^{\prime}\left(\dot{w}_{t}\right)<0, f^{\prime}\left(G \dot{D P} h_{t}^{*}\right)>0 .
\end{gathered}
$$

\section{Proof.}

Remember that $M R_{t}$ is a value that managers have to predict such as :

$$
M R_{t}^{*}=1-\frac{w_{t}}{p_{t} \cdot G D P h_{t}^{*}} .
$$

Taking the differential yields ${ }^{8}$ :

$$
d M R_{t}^{*}=-\frac{1}{p_{t-1} \cdot G D P h_{t-1}} d w_{t}+\frac{w_{t-1} \cdot G D P h_{t-1}}{\left(p_{t-1} \cdot G D P h_{t-1}\right)^{2}} d p_{t}+\frac{w_{t-1} \cdot p_{t-1}}{\left(p_{t-1} \cdot G D P h_{t-1}\right)^{2}} d G D P h_{t}^{*} .
$$

\footnotetext{
${ }^{8}$ In order to take the total differential between two given instants, we suppose that the end of period $T-1$ is the instant $t-1$ and that the end of period $T$ is the instant $t$.
} 
It follows that variations between period $T$ and period $T-1$ may be captured such as : $\Delta M R_{t}^{*}:=$ $M R_{t}^{*}-M R_{t-1} \approx d M R_{t}^{*}$. After some algebraic manipulations, we get :

$$
\frac{\Delta M R_{t}^{*}}{M R_{t-1}}=: R \dot{M}_{t}^{*} \approx \frac{w_{t-1}}{p_{t-1} \cdot G D P h_{t-1}-w_{t-1}}\left(\frac{\Delta p_{t}}{p_{t-1}}-\left(\frac{\Delta w_{t}}{w_{t-1}}-\frac{\Delta G D P h_{t}^{*}}{G D P h_{t-1}}\right)\right),
$$

that is :

$$
\dot{R} M_{t} \approx \frac{w_{t-1}}{p_{t-1} \cdot G D P h_{t-1}-w_{t-1}}\left(\dot{p}_{t}-\left(\dot{w}_{t}-G \dot{D P} h_{t}^{*}\right)\right) .
$$

For ease of exposition :

$$
A_{t-1}:=\frac{w_{t-1}}{p_{t-1} \cdot G D P h_{t-1}-w_{t-1}} \text { then } R \dot{M}_{t} \approx A_{t-1}\left(\dot{p}_{t}-\left(\dot{w}_{t}-G \dot{D P} h_{t}^{*}\right)\right) .
$$

The bequest $A_{t-1}$ is the nominal wage rate at the end of period $T-1$ by unit of gross operating surplus of $T-1$. Remark also that $\left(\dot{w}_{t}-G \dot{D P} h_{t}^{*}\right)=: U \dot{W} C_{t}^{*}$ is the expected growth rate of the unitary wage cost, so that :

$$
R M_{t} \approx A_{t-1}\left(\dot{p}_{t}-U \dot{W} C_{t}^{*}\right)
$$

This expression yields the sharing of the value added within a dynamic context. At the beginning of period $T$, the manager cannot modify $A_{t-1}$. However, if he decides to increase (real) labor productivity between $T$ and $T-1$, he may expect to improve the growth of the margin rate, and therefore to match capital owners' objectives. If he behaves in accordance with mark-up pricing, which does really make sense in a monopolistic competition environment, the growth of the unitary wage cost may be compensated for an increase of $\dot{p}_{t}$. On the contrary, if employees arrive at increasing the nominal wage rate (labor productivity remaining constant), then the margin rate decreases and therefore the employees' cake share becomes slightly bigger.

Let us now connect the variations of the unemployment rate with the sharing of the value added and the expectations resulting from managers' behavior. The link is concerned with markup pricing. Remember that the variations of the unemployment rate, in Eqs. (10) and (11) rely on mark-up pricing $\dot{p}$. However, as can be seen in the previous section, the mark-up behavior is the result of conflicts for the value-added sharing. Indeed rewriting Eq. (12) yields :

$$
\dot{p}_{t} \approx \frac{R \dot{M}}{A_{t-1}^{*}}+U \dot{W} C_{t}^{*}
$$

On the one hand, managers fix prices in accordance with the expected margin rate $\dot{M} R_{t}^{*}$, which reflects the future conflicts about the sharing of the value added. On the other hand, as shown in the previous sections, managers predict the value of $G D P$ and $G D P h$ in order to determine the level of employment at the beginning of period $T$. 
Theorem 6.1 From definitions (A0) and (B0)-(B2), if managers behave in accordance with markup pricing Eq. (13) and behave according to

( $)$ (A1) then:

$$
\begin{aligned}
u_{t}-u_{t-1} \approx & \sum_{\ell=1}^{n}\left(\dot{\beta}_{\ell}-\dot{\alpha}_{\ell}+G \dot{D} P h_{t-\ell}\right)+R A_{t}+W \dot{P} O P_{t} \\
& +\sum_{\ell=1}^{n}\left(-\frac{I_{t-\ell}-S_{t-\ell}}{G D P_{t-\ell-1}}-\frac{E X P_{t-\ell}-I M P_{t-\ell}}{G D P_{t-\ell-1}}-\frac{R R_{t-\ell-1}-R V_{t-\ell-1}}{G D P_{t-\ell-1}}+\frac{R M_{t-1}^{*}}{A_{t-2}}+U \dot{W} C_{t-1}^{*}\right) .
\end{aligned}
$$

(ıi) (A2) then:

$$
\begin{aligned}
u_{t}-u_{t-1} \approx & \sum_{\ell=1}^{n}\left(\dot{\beta}_{\ell}-\dot{\alpha}_{\ell}+G \dot{D P} h_{t-\ell}\right)+\dot{R A_{t}}+W \dot{P} O P_{t} \\
& -\frac{I_{t-1}-S_{t-1}}{G D P_{t-2}}-\frac{E X P_{t-1}-I M P_{t-1}}{G D P_{t-2}}-\frac{R R_{t-2}-R V_{t-2}}{G D P_{t-2}}+\frac{R M_{t-1}^{*}}{A_{t-2}}+U \dot{W} C_{t-1}^{*} .
\end{aligned}
$$

\section{Proof.}

Substituting Eq. (13) in Eqs. (9) and (11) respectively yields the desired result.

Importantly, Theorem 6.1 combines the variations of the unemployment rate with two types of behavior :

( $)$ Managers' mark-up pricing resulting from the future view they have about the conflict for the value added, that is, the expected growth rate of the margin rate $\left(\dot{M} R_{t}^{*}\right)$ and the expected growth rate of the unitary wage cost $\left(U \dot{W} C_{t}^{*}\right)$ (that reflects conflict between managers and employees);

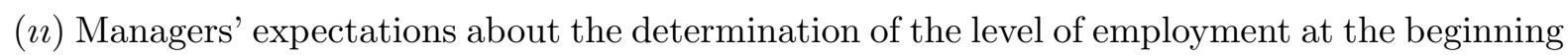
of period $T$, that is, expectations on $G D P h$ and $G D P$, which are based on managers' strategy to improve the cake share and to defend capital owners' remuneration, respectively.

\section{Conclusion}

Although we refuse the same equilibrium that Keynes made use in his general theory, that of $I=S$, we follow Keynes on many things : future, unemployment and individualism. For Keynes (1936), individualism implies the variety of the existence and this variety is the strongest machine to improve future. But the level of the unemployment rate is the consequence of the excess of individualism as it appears in the modern capitalist regime. Indeed, Keynes (1936, Chapter 24, Section 3, p.381) wrote :

"[I]t is certain that the world will not much longer tolerate the unemployment which, apart from brief intervals of excitement, is associated - and, in my opinion, inevitably associated - with present - day capitalistic individualism."

In his theory, Keynes suggests that many issues are possible without making sacrifice about individualism and profitability. One has just to avoid the excess of individualism we may find 
on places that Keynes identifies as casinos. Indeed, speculation has become much less risky and much more profitable than investing in the long run by gauging the marginal efficiency of capital. Then, investment may become the by-product of casino activities. Consequently, one may save the "Manchester System" if one exerts some control over the organization of financial markets liquidity (Chapter 12, Section 6).

We may adopt many arguments of Keynes' theory. But this theory is silent about the banking system since the identity between investment and savings is postulated. Economists have the possibility to admit that consumption expenditures is subject to time lags à la Robertson. Subsequently, the identification of the role of banking credits (a part of the monetary creation) is rather immediate. On the one hand, the banking organization together with that of financial markets play a decisive function in the determination of the employment level. On the other hand, conflicts for the value-added sharing is also a fundamental component of the employment determination. In sum, for either banking and financial systems or conflicts for the value-added sharing, the excesses of individualism, i.e. "greed and irresponsibility", may be of devastating importance.

\section{References}

[1] Duménil G. and Lévy D. (1996), "La dynamique du capital", PUF.

[2] Godley W. and Lavoie M. (2007), Monetary Economics, Palgrave Macmillan.

[3] Hicks (1965), Capital and Growth, University Press, Oxford (ed. 1969).

[4] Keynes, J.-M. (1936), The General Theory of Employment, Interest and Money, Macmillan Cambridge University Press, The collected writtings (eds. 1973).

[5] Mussard, S and B. Philippe (2009), "Okun's Law, Creation of Money and the Decomposition of the Rate of Unemployment", Economics Letters vol. 102(1), 7-9. 